\title{
Silver Russell syndrome in a preterm girl with 8q12.1 deletion encompassing PLAG1.
}

José Ramón Fernández-Fructuoso ${ }^{1}$, Cristina De la Torre-Sandoval ${ }^{1}$, Madeleine Harbison ${ }^{2}$, Sandra Chantot-bastaraud ${ }^{3}$, I. Temple ${ }^{4}$, Jose Maria Lloreda-Garcia ${ }^{1}$, Maria Olmo-Sanchez ${ }^{1}$, and Professor Irene Netchine ${ }^{5}$

${ }^{1}$ Hospital Universitario General de Santa Lucia

${ }^{2}$ Ichan School of Medicine at Mount Sinai

${ }^{3}$ UF de Génétique Chromosomique, Hôpital Armand-Trousseau, APHP, Paris, 75012,

France

${ }^{4}$ Southampton University Hospitals NHS Trust

${ }^{5}$ Hôpital Trousseau, INSERM U938, UPMC, Paris 6, France

March 23, 2021

\begin{abstract}
Silver Russell syndrome (SRS) is a congenital disorder characterised by intrauterine growth retardation (IUGR), feeding difficulties and postnatal growth retardation. In a small number of cases PLAG1 variants have been described (OMIM \#618907). PLAG1 haploinsufficiency decreases IGF2 expression and produces a Silver Russell syndrome like phenotype. Here, we describe the phenotype and molecular features of a 26 months girl with clinical features of SRS and a de novo $2.1 \mathrm{Mb}$ deletion encompassing PLAG1 is reported in association with clinical features suggestive of SRS.
\end{abstract}

\section{Hosted file}

Silver Russell syndrome 8q12-1 deletion.doc available at https://authorea.com/users/ 374773/articles/492218-silver-russell-syndrome-in-a-preterm-girl-with-8q12-1-deletionencompassing-plag1 